\title{
SÍNTESE DA ZEÓLITA 5A OBTIDA POR TROCA IÔNICA A PARTIR DE RESÍDUO DA INDÚSTRIA DE PAPEL
}

\author{
J. C. MOREIRA ${ }^{1}$, K. VOLLMANN ${ }^{1}$, L. B. BORTOLATTO ${ }^{1}$, L. MÜLLER ${ }^{1}$, H. G. RIELLA ${ }^{1}$, N. C. \\ KUHNEN $^{1}$ \\ ${ }^{1}$ Universidade Federal de Santa Catarina, Departamento de Engenharia Química e Engenharia de \\ Alimentos \\ E-mail para contato: jarina.moreira@ posgrad.ufsc.br
}

\begin{abstract}
RESUMO - A temática proposta surgiu diante à necessidade de identificar os resíduos gerados pela indústria de papel e o destino dado a eles, e assim avaliar a possibilidade de aproveitamento na síntese de zeólitas de um resíduo proveniente das indústrias de papel do estado de Santa Catarina, visando minimizar o impacto ambiental e diminuir os custos com o acondicionamento. As zeólitas são materiais de larga escala comercial, devido às suas propriedades físicas e químicas. Nos processos de sínteses de zeólitas, a procura por matérias-primas mais econômicas resultou na utilização de argilominerais, sendo o caulim o mais empregado. A indústria do papel produz como subproduto um material de origem mineral, constituído de caulim, carbonato de cálcio $\left(\mathrm{CaCO}_{3}\right)$ e celulose. A purificação do resíduo foi feita por tratamento químico e térmico, através de lavagem ácida com $\mathrm{HCl}$ para remoção de $\mathrm{CaCO}_{3}$, seguida de calcinação para remoção da celulose e obtenção do metacaulim. A zeólita $4 \mathrm{~A}$ foi sintetizada sob condições hidrotérmicas a $150{ }^{\circ} \mathrm{C}$ por $4 \mathrm{~h}$. A zeólita 5A foi obtida por troca iônica com zeólita $4 \mathrm{~A}$ e $\mathrm{CaCl}_{2}$. Os materiais obtidos foram caracterizados por difração de raios $\mathrm{x}$, fluorescência de raios $\mathrm{x}$, espectroscopia de absorção na região do infravermelho e espectrometria de absorção atômica. O resíduo proveniente da indústria de papel mostrou-se uma excelente matéria-prima para produção da zeólita 5A.
\end{abstract}

\section{INTRODUÇÃO}

A gestão de resíduos é um problema que atinge o mundo todo, tendo em vista o elevado custo do manejo, tratamento e disposição. Os governos estão tentando tratar o problema na sua origem, ou seja, reduzindo a geração de resíduos e incentivando a reciclagem e o reuso, o que resultará em menor quantidade de resíduos e consequientemente em economia nos custos com o seu gerenciamento, e também na redução do número de aterros, já que este é o meio mais barato e comum para a disposição de resíduos (Tardio, 2008).

O consumo de papéis tem apresentado elevadas taxas de crescimento nos últimos anos, o que acarretou a uma expansão na demanda de celulose, principal matéria-prima do papel, o que foi favorável para o Brasil, em função das vantagens competitivas que detém no segmento de produção da madeira. O Brasil ocupa hoje o quarto lugar na produção mundial de celulose e o nono lugar na produção de papel (BRACELPA, 2014), sendo que o estado de Santa Catarina 


\section{9 a 22 de outubro de 2014 \\ Florianópolis/SC}

conserva posição de destaque no cenário nacional, ocupando a terceira posição na produção de papel, e a quarta posição na produção de celulose (Carvalho et al., 2005).

Para a fabricação do papel são usados dois tipos de matérias-primas: as fibrosas, como as fibras de celulose e matérias-primas não fibrosas, nas quais destacam-se produtos inorgânicos conhecidos como cargas, que incorporadas à superfície das fibras celulósica tem como finalidade propiciar maior uniformidade e melhorar características como alvura, lisura e opacidade. Entre os principais produtos inorgânicos usados como carga temos carbonato de cálcio e o caulim (Lébeis, 2003). Assim o resíduo gerado na fabricação de papel é composto basicamente por uma mistura de $45 \%$ de caulim, $45 \%$ carbonato de cálcio e $10 \%$ de celulose.

Devido à presença de celulose, o resíduo contribui para a redução do consumo de combustível durante a etapa de queima (Carvalho; Salvador, 1997). O caulim uma argila que contém a caulinita que é um argilomineral que possui razão Silício/Alumínio igual a 1, próxima da requerida para a síntese da zeólita A (Santos, 1989). Assim, com propriedades apropriadas ao uso ambiental, julgou-se adequado estudar o desenvolvimento de processos de síntese de zeólita a partir de caulins calcinados obtidos pela purificação de um resíduo da indústria de papel.

As zeólitas são aluminossilicatos cristalinos de ampla aplicação industrial devido às suas propriedades físicas e químicas. A zeólita A é especialmente atrativa em suas aplicações devido possuir poros de tamanho efetivo que podem ser facilmente variados pela troca de íon, nesse tipo de zeólita ao substituir-se sódio por potássio, a zeólita vai da forma 4A para 3A, já a substituição de sódio por cálcio resulta na forma $5 \mathrm{~A}$, os números 3, 4 e 5 representam dimensão de abertura dos poros em ângstrons (Cardoso et al., 1995).

\section{MATERIAIS E MÉTODOS}

\subsection{Metodologia de Purificação do resíduo}

O processo de purificação do resíduo ocorreu em duas etapas. A primeira etapa consiste na calcinação do resíduo para a eliminação da celulose. A segunda etapa foi realizada a partir da lavagem ácida do resíduo, na qual $85 \mathrm{~g}$ do resíduo foram adicionadas a $1 \mathrm{~L}$ de solução de $\mathrm{HCl} 1.8 \mathrm{~mol} \mathrm{~L}^{-1} \mathrm{sob}$ agitação, em seguida foi lavado e filtrado. $\mathrm{O}$ sólido precipitado (caulim) foi calcinado a $850{ }^{\circ} \mathrm{C}$ por 2 h e o sobrenadante resultante do processo de filtração passou por evaporação para obtenção de cloreto de cálcio, decorrente da reação do $\mathrm{HCl}$ com $\mathrm{CaCO}_{3}$ presente no resíduo.

\subsection{Metodologia de Síntese da zeólita 4A}

A síntese da zeólita 4A foi realizada sob autoclavagem estática, a partir da reação hidrotérmica de $3 \mathrm{~g}$ de metacaulim e $30 \mathrm{ml}$ de solução de $\mathrm{NaOH}$ 1,25 mol. $\mathrm{L}^{-1}$ em um reator de teflon/alumínio. O tempo de reação foi de 4 horas a $150{ }^{\circ} \mathrm{C}$. O tempo de envelhecimento foi de 
aproximadamente $4 \mathrm{~h}$. $\mathrm{O}$ sólido resultante foi lavado e centrifugado até $\mathrm{pH}$ igual a 9 , em seguida a amostra foi seca em estufa a $100{ }^{\circ} \mathrm{C}$ durante 6 horas.

\subsection{Obtenção da zeólita 5A}

A obtenção da zeólita $5 \mathrm{~A}$ foi realizada por troca iônica com a zeolita 4A. O cátion trocável da zeólita 4A é sódio e na zeólita 5A é o cálcio, asssim, o cloreto de cálcio proveniente do resíduo foi utilizado na troca iônica como uma fonte de íons de cálcio. O processo de troca iônica foi realizado em um reator batelada com água, a partir de $6 \mathrm{~g}$ da zeólita 4A em $40 \mathrm{~mL}$ de solução de $\mathrm{CaCl}_{2}$ 0,18 mol.L $\mathrm{L}^{-1}$ em temperatura ambiente $\left(25^{\circ} \mathrm{C}\right)$ durante $1 \mathrm{~h}$. Após este procedimento, a suspenção foi filtrada a vácuo e fração sólida foi lavada com água destilada, em seguida, o produto foi seco a $100^{\circ} \mathrm{C}$ durante 6 horas, procedimento adaptado de Melo e Riella (2010). A zeólita 5A obtidas por troca iônica foi caracterizada, assim como a zeólita de partida e a composição dessas zeólitas foram determinadas por absorção atômica.

\subsection{Caracterização dos materiais}

As técnicas de caracterização a seguir foram empregadas para a análise das amostras de resíduo, de metacaulim e das zeólitas produzidas.

As medidas de DRX foram realizadas em um difratômetro Philips (modelo X'pert), do Laboratório de Microscopia Eletrônica, do Departamento de Engenharia Mecânica da Universidade Federal de Santa Catarina (UFSC). Os padrões do pó foram coletados no modo contínuo com velocidade de varredura de $0,5 \mathrm{~min}^{-1}(2 \theta)$. Radiação $\mathrm{Cu} \mathrm{Ka}$ foi usado com o tubo operado a $40 \mathrm{kV}$ e $30 \mathrm{~mA}$.

As medições de FTIR foram realizadas com um espectrômetro Shimadzu FTIR (modelo IR Prestige-21) do Laboratório de Controle de Processos (LCP) da Universidade Federal de Santa Catarina (UFSC). As amostras foram preparadas em pastilhas de $\mathrm{KBr}$.

Os ensaios de FRX foram realizados em um Espectrômetro da marca Philips, modelo PW 2400, por dispersão de comprimento de onda (WDXRF), no Laboratório de análises do SENAI de Criciúma-SC. E as análises por espectrometria de absorção atômica foram realizadas para as zeólitas 4A e 5A, utilizando-se um espectrômetro de absorção atômica PinAAcle 900T e Fotômetro de chama marca Cole-Parmer. Antes da leitura do teor de $\mathrm{Ca}^{+2} \mathrm{e} \mathrm{Na}^{+}$por absorção atômica, foi necessário fazer a abertura da amostra, da seguinte forma: $0,5 \mathrm{~g}$ da zeólita foram digeridos em água régia $\left(\mathrm{H}_{2} \mathrm{O}: \mathrm{HNO}_{3}: \mathrm{HCl}\right.$ a 2,5:1:3) e deixadas durante $15 \mathrm{~h}$, as amostras foram filtradas e adicionadas novamente a mesma solução, seguida de refluxo por $2 \mathrm{~h}$ e filtração. A fase micelar remanescente foi dissolvida em $\mathrm{HCl} 2 \%$ e em seguida foram feitas as diluições específicas para cada metal a ser quantificado, sendo $5 \mathrm{mg} \mathrm{L}^{-1}$ para o espectrômetro de absorção atômica e $10 \mathrm{mg} \mathrm{L}^{-1}$ para o fotômetro de chama. 


\section{RESULTADOS E DISCUSSÕES}

\subsection{Análise química do Metacaulim}

A composição química do resíduo antes e após o processo de purificação foi determinada por fluorescência de raios-X (FRX) e resultado em óxidos estão descriminados na Tabela 1. Os dados mostrados evidenciam que houve diminuição significativa do $\mathrm{CaO}$, passando de $32.35 \%$ do resíduo in natura, para 2,03\% após lavagem ácida com $\mathrm{HCl}$ a $1,8 \mathrm{~mol} \mathrm{~L}^{-1}$.

Tabela 1. Fluorescência de raios X de resíduo antes e após a purificação.

\begin{tabular}{lcc}
\hline $\begin{array}{l}\text { Elemento/ } \\
\text { Composição }\end{array}$ & $\begin{array}{c}\text { Resíduo } \\
\text { in natura }\end{array}$ & $\begin{array}{c}\text { Purificação a } \\
\mathbf{1 , 8 m o l ~} \mathbf{~}^{-\mathbf{1}} \mathbf{\text { a 850 }}\end{array}{ }^{\circ} \mathbf{C}$ \\
\hline $\mathrm{SiO}_{2}$ & 7,69 & 53,61 \\
\hline $\mathrm{Al}_{2} \mathrm{O}_{3}$ & 6,08 & 37,32 \\
\hline $\mathbf{C a O}$ & $\mathbf{3 2 , 3 5}$ & $\mathbf{2 , 0 3}$ \\
\hline $\mathrm{Fe}_{2} \mathrm{O}_{3}$ & 0,17 & 1,64 \\
\hline $\mathrm{K}_{2} \mathrm{O}$ & $<0,05$ & 0,48 \\
\hline $\mathrm{MgO}$ & 0,62 & 1,63 \\
\hline $\mathrm{MnO}$ & $<0,05$ & $<0,05$ \\
\hline $\mathrm{Na}_{2} \mathrm{O}$ & 0,07 & 0,34 \\
\hline $\mathrm{P}_{2} \mathrm{O}_{5}$ & 0,11 & 0,16 \\
\hline $\mathrm{TiO}_{2}$ & 0,15 & 1,84 \\
\hline $\mathrm{Perda} \mathrm{Fogo}$ & 52,64 & 0,60 \\
\hline
\end{tabular}

Após a calcinação as quantidades de $\mathrm{Al}_{2} \mathrm{O}_{3}$ e $\mathrm{SiO}_{2}$ aumentam devido a queima da celulose, tendo como resultado final o metacaulim. $\mathrm{O}$ metacaulim resultante do processo de purificação apresenta teores de $\mathrm{SiO}_{2}$ de 53,61\% e teores de $\mathrm{Al}_{2} \mathrm{O}_{3}$ de 37,32\%, valores que se aproximam dos especificados por Santos (1989), que são de 46,54\% para o $\mathrm{SiO}_{2}$ e 39,5\% para o $\mathrm{Al}_{2} \mathrm{O}$. Assim, é possível avaliar que o metacaulim apresenta uma razão Si/Al próxima da requerida para a síntese da zeólita A, não necessitando a adição de silício ou alumínio.

\subsection{Difratograma de raios-X do resíduo antes e após a purificação e da zeólita 4A}

A Figura 1 apresenta o difratograma do resíduo antes e após a purificação e da zeólita sintetizada. $\mathrm{O}$ resíduo apresenta fases cristalinas correspondentes à calcita, caulinita e celulose $\mathrm{e}$ após o tratamento químico e a calcinação observa-se o desaparecimento destes picos. Através do tratamento térmico ocorre a desidroxilação de caulinita, onde observa-se o desaparecimento dos picos referentes à mesma comprovando a transformação do caulim em metacaulim. 


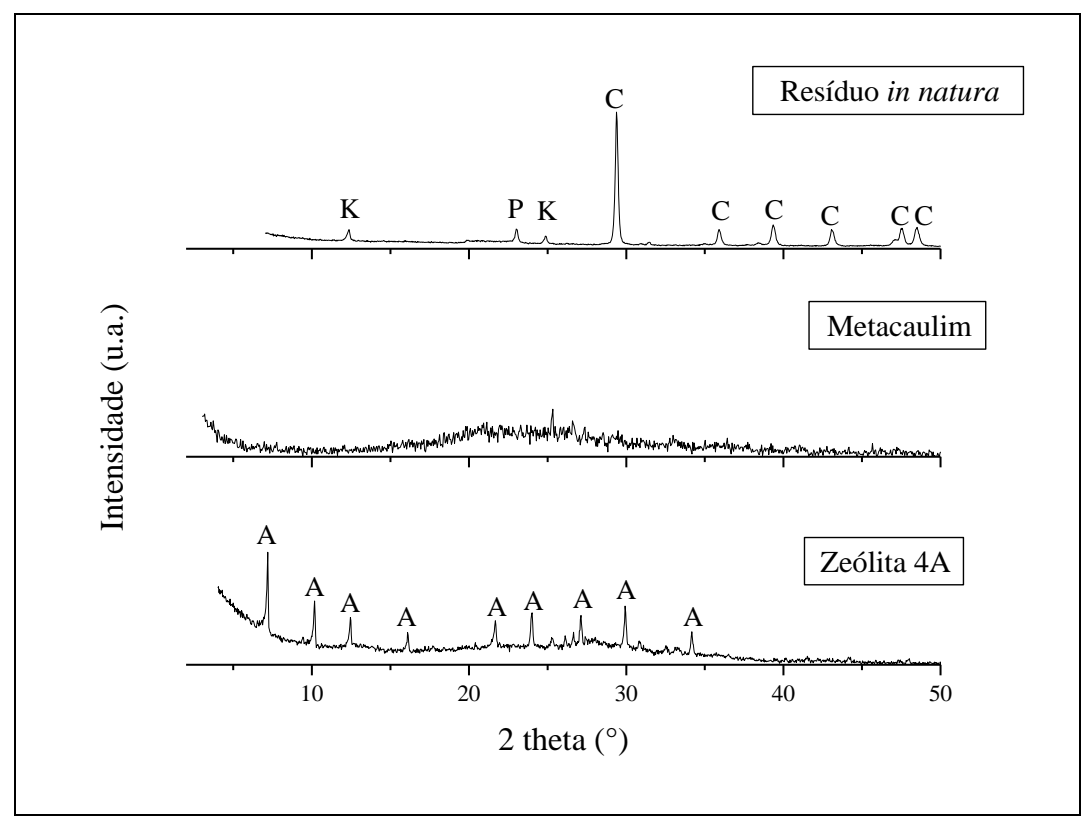

Figura 1. Difratograma de raios $\mathrm{X}$ do resíduo antes e após a purificação e zeólita 4A: caulinita (K), calcita (C), celulose (P) e zeólita 4A (A).

O difratograma também ilustra a zeólita 4A. A posição dos picos obtidos na zeólita sintetizada foi comparada com picos descritos na literatura. Assim, a amostra apresenta picos correspondentes aos picos característicos da zeólita $\mathrm{A}$, com os valores de 2 theta em: $7,18^{\circ}$; $10,17^{\circ} ; 12,46^{\circ} ; 16,11^{\circ} ; 21,85^{\circ} ; 24^{\circ} ; 26.2^{\circ} ; 27.2^{\circ}, 30^{\circ}, 30,9^{\circ} ; 31,7^{\circ} ; 32,6^{\circ} ; 33,4^{\circ}$ e $34,7^{\circ}$ que foram relatado por Treacy e Higgins (2001). Portanto, temos que a zeólita 4A foi a principal fase cristalina.

\subsection{Interpretação dos Espectros de Infravermelho (FTIR) do metacaulim e da zeólita 4A}

A Figura 2 apresenta o espectro de FTIR do metacaulim e da zeólita 4A. A amostra de metacaulim contem alguns traços de celulose, devido a bandas que aparece em $1636 \mathrm{~cm}^{-1}$ e que representa o grupo $\mathrm{OH}$ presente na celulose, as outras bandas em $1083 \mathrm{~cm}^{-1}, 801 \mathrm{~cm}^{-1} \mathrm{e} 464 \mathrm{~cm}^{-1}$ representam as modificações de caulim em metacaulim. As absorções que ocorrem em $1083 \mathrm{~cm}^{-1}$ correspondem às interações $\mathrm{Si}-\mathrm{O}-\mathrm{Si}, \mathrm{em} 801 \mathrm{~cm}^{-1}$ temos as interações $\mathrm{Al}-\mathrm{O}$ e as bandas em 464 $\mathrm{cm}^{-1}$ são de acoplamento O-Si-O característicos deste argilomineral (Gomes, 1986). A largura das três últimas bandas sugere que a estrutura está desordenada (Cristobal et al., 2010). A presença de material zeolítico foi confirmada através da banda em $1004 \mathrm{~cm}^{-1}$, pois bandas localizadas próximas a $1000 \mathrm{~cm}^{-1}$ é característica da ligação $\mathrm{Si}-\mathrm{O}-\mathrm{Al}$ do tetraedro $\mathrm{TO}_{4}$ de unidades primárias de construção (Maia et al., 2007). Entretanto, são as bandas ao redor de 680,550 e $456 \mathrm{~cm}^{-1}$ que indicaram a cristalização da zeólita A. As bandas em $680 \mathrm{~cm}^{-1}$ representam estiramentos simétricos típicos das vibrações internas primárias $\mathrm{T}-\mathrm{O}(\mathrm{Si}, \mathrm{Al})$. A banda próxima a $550 \mathrm{~cm}^{-1}$ está conectada com a vibração do anel duplo de quatro tetraedros (D4R), que é dominante na 
unidade secundária de construção da estrutura da zeólita A (Markovic, et al., 2003). Uma banda em $463 \mathrm{~cm}^{-1}$ caracteriza a vibração interna do D4R (Andrade; Silva, 2011), ainda foi visualizada uma banda localizada a $800 \mathrm{~cm}^{-1}$, referente a presença de metacaulim, material de partida, que possivelmente não reagiu totalmente, assim a amostra está de acordo com a interpretação dos resultados obtidos por DRX.

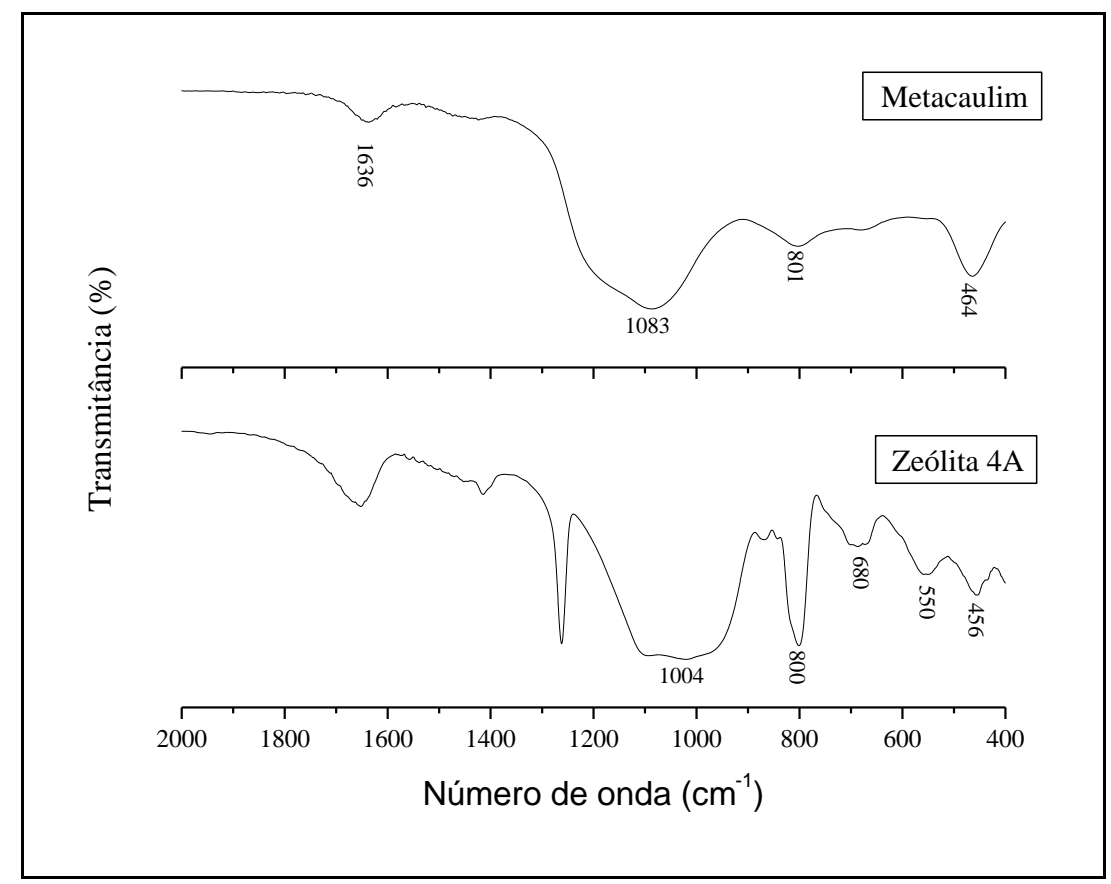

Figura 2: Espectros de absorção na região do Infravermelho do metacaulim e da zeólita 4A.

\subsection{Interpretação da análise de Absorção Atômica da zeólita 5A}

A partir do resultado de absorção atômica foi possível calcular a Percentagem de Troca Catiônica (PTC), que foram calculado pela diferença do teor de sódio na amostra e definida pela equação 1:

$$
\mathrm{PTC}=100\left(\mathrm{C}_{0}-\mathrm{C}_{\mathrm{f}}\right) / \mathrm{C}_{0}
$$

$\mathrm{C}_{0}$ e $\mathrm{C}_{\mathrm{f}}$ são as concentrações de sódio inicial (antes da troca) e final (depois da troca), respectivamente. A Tabela 2 apresenta os valores obtidos para a Percentagem de Troca Catiônica.

Tabela 2: Análise de Espectrometria de Absorção atômica da zeólita 5A.

\begin{tabular}{cccccc}
\hline Zeólita & $\mathbf{N a}^{+}(\%)$ & $\mathbf{C a}^{+\mathbf{2}}(\boldsymbol{\%})$ & $\begin{array}{c}\text { Temperatura } \\
\text { de troca }\end{array}$ & Tempo de troca & PTC \\
\hline $\mathbf{4 A}$ & 14,90 & 0,37 & - & - & $0 \%$ \\
\hline $\mathbf{5 A}$ & 6,95 & 13,30 & $1 \mathrm{~h}$ & $25^{\circ} \mathrm{C}$ & $53,35 \%$ \\
\hline
\end{tabular}


A eficiência da capacidade de troca catiônica da zeólita permanece em torno de 53,35\% na primeira hora, resultados relatados por Loila (2012) sugerem que, para este tipo de aplicação, não se faz necessário empregar elevados tempos de contato, uma vez que a troca entre os íons $\mathrm{Ca}^{2+} \mathrm{da}$ água é feita rapidamente pelos íons $\mathrm{Na}^{+}$da zeólita.

\section{CONCLUSÃO}

A intensidade dos picos observados no difratograma de raios $\mathrm{x}$ indica que a zeólita sintetizada apresenta boa cristalinidade. O resíduo proveniente das indústrias de papel mostrou-se como uma excelente matéria-prima para produção de zeólita A, sendo dessa forma mais uma alternativa na tentativa de minimizar os impactos ambientais. Além disso, em tempos menores temos um bom desempenho para a obtenção da zeólita $5 \mathrm{~A}$ por troca iônica.

\section{REFERÊNCIAS BIBLIOGRÁFICAS}

ANDRADE, J. C. R. A.; SILVA, L. R. D. Nitrato de amônio ocluído em zeólita 4A: lixiviação e absorção de nitrogênio no cultivo de milho. Quim. Nova, v. 34, n. 9, p.1562-1568, 2011.

BRACELPA, Associação Brasileira de Celulose e Papel. Dados do Setor. mar, 2014. Disponível em: http//www.bracelpa.org.br, acessada em abril 2014.

CARDOSO, D.; GONZALEZ. E. A. U.; JOHN, S. L. $2^{o}$ Curso Iberoamericano sobre peneiras moleculares. São Carlos: CYTED. Rede Temática V. A: Peneiras Moleculares, 1995.

CARVALHO, E. A.; SALVADOR, L. M. A.; Caulim e Carbonato de Cálcio: Competição na indústria de papel. Série Est. e Doc., v. 41, p. 26. CETEM/CNPq, 1997.

CARVAlHO, L. C. J; PEREIRA, J. G. S.; BINOTTO, P. A. Cadeia Produtiva de Papel e Celulose. Sec. de Des. do Estado de Santa Catarina, 2005.

CRISTÓBAL, A.G. S.; CASTELlÓ, R.; LUENGO, M.A.M.; VIZCAYNO, C.; Zeolites prepared from calcined and mechanically modified kaolins A comparative study. Appl. Clay Sci, v. 49, p. 239-246, 2010.

GOMES, C. F. Argilas: o que são e para que servem. Lisboa: Fundação Calouse Gulbenkian, 1988.

LÉBEIS, V. D. L. Viabilidade do uso do resíduo da fabricação do papel em argamassas. Campinas. Dissertação de mestrado. Departamento de Engenharia Civil. Universidade Estadual de Campinas. 2003. 
LOIOLA, A.R.; ANDRADE, J.C.R.A.; SASAKI, J.M; SILVA, L.R.D. Structural analysis of zeolite $\mathrm{NaA}$ synthesized by a cost-effective hydrothermal method using kaolin and its use as water softener. J. Colloid Interface Sci. v. 367, p.34-39, 2012.

MAIA, A. A. B.; SALDANHA, E.; ANGÉlICA, R. S.; SOUZA, C. A. G.; NEVES, R.F. Utilização de rejeito de caulim da Amazônia na síntese da zeólita A. Cerâmica, v. 53, p. 319-324, 2007.

MARKOVI, S.; DONDUR, V.; DIMITRIJEVIC, R. FTIR spectroscopy of framework aluminosilicate structures: carnegieite and pure sodium nepheline. J. Mol. Struct. v. 654, p. 223234, 2003.

MELO, C. R.; RIELLA, H. G.; Síntese de zeólita tipo NaA a partir de caulim para obtenção de zeólita 5A através de troca iônica. Cerâmica. v. 56, p. 340-346, 2010.

SANTOS, P. S. Ciência e tecnologia das argilas. $2^{a}$ ed. São Paulo: Edgard Blücher Ltda., v. 1, 1989.

TARDIO, O. L. H. A questão dos resíduos industriais. CENED - Centro Nacional de Ensino a Distancia. 2008. Disponível em: http://www.cenedcursos.com.br/a-questao-dos-residuosindustriais.html. Acessado em 13 de novembro 2013.

TREACY, M.J.; HIGGINS, J.B. Collection of simulated XRD powder patterns for zeolites. $4^{\mathrm{a}}$ ed., p. 379. Elsevier, Amsterdam, The Netherlands, 2001. 